\title{
HOT-DEFORMATION BEHAVIOR AND A MODIFIED PHYSICALLY BASED CONSTITUTIVE MODEL FOR As-CAST $12 \%$ Cr STEEL DURING HOT DEFORMATION
}

\author{
VROČA DEFORMACIJA IN MODIFICIRANA PLASTIČNOST - \\ KONSTITUTIVNI MODEL ZA OBNAŠANJE LITEGA JEKLA Z \\ $12 \%$ Cr MED VROČO DEFORMACIJO
}

\author{
Xuezhong Zhang, Fei Chen, Yongxing Jiao, Jiansheng Liu* \\ School of Materials Science and Engineering, Taiyuan University of Science and Technology, No. 66 Waliu Road, \\ Wanbailin District, Shanxi, Taiyuan 030024, PR China \\ Prejem rokopisa - received: 2020-02-17; sprejem za objavo - accepted for publication: 2020-04-28
}

doi:10.17222/mit.2020.032

\begin{abstract}
The development of ultra-supercritical thermal-power units has a significant effect on energy conservation and emission reduction. Based on a uniaxial isothermal compression test, the hot-plastic-deformation behavior of the as-cast $12 \% \mathrm{Cr}$ ultra-supercritical rotor steel was studied systematically. The flow stress/strain curves for the as-cast $12 \% \mathrm{Cr}$ steel were obtained under the conditions of a deformation temperature ranging from $1173 \mathrm{~K}$ to $1573 \mathrm{~K}$ and strain rate ranging from 0.001 to $1 \mathrm{~s}^{-1}$. By analyzing the evolution characteristics of the macro-flow stress, the influence of deformation-process parameters such as the strain, deformation rate and temperature on the flow stress was studied. A physically based constitutive model was established to describe the high-temperature flow stress, and the model was modified to improve its accuracy. The average absolute relative error of the modified model is $12.2 \%$ and the root-mean-square error is $7.0 \mathrm{MPa}$, so that its prediction accuracy is higher than that of the unmodified model.

Keywords: $12 \% \mathrm{Cr}$, ultra-supercritical rotor, high-temperature plastic deformation, constitutive model
\end{abstract}

Razvoj novih ultra-superkritičnih rotorjev za termo-energetske objekte ima pomemben pomen pri zmanjšanju porabe energije in onesnaževanja okolja. Avtorji so na osnovi enoosnega izotermičnega tlačnega preizkusa sistematično študirali vročo plastično deformacijo litega jekla z $12 \% \mathrm{Cr}$, namenjenega za ultra-superkritične rotorje. Krivulje tečenja litega jekla z $12 \% \mathrm{Cr}$ so določili $\mathrm{z}$ njegovo deformacijo $\mathrm{v}$ temperaturnem območju med $1173 \mathrm{~K}$ in $1573 \mathrm{~K}$ ter hitrostih deformacije od $0,001 \mathrm{~s}^{-1}$ do $1 \mathrm{~s}^{-1}$. Analizirali so značilnosti razvoja makronapetosti tečenja in študirali vpliv parametrov procesa deformacije kot so deformacija, hitrost in temperatura deformacije na napetost tečenja. Postavili so fizikalni konstitutivni model za opis visoko temperaturne napetosti tečenja in ga dodatno modificirali za izboljšanje njegove točnosti. Povprečna absolutna relativna napaka modificiranega modela je $12,2 \%$ in povprečni kvadratni koren napake je 7,0 MPa, kar je precej manjša napaka kot so jo dosegli $\mathrm{z}$ nemodificiranim modelom

Ključne besede: jeklo z 12 \% Cr v litem stanju, ultra-superkritični rotor, visokotemperaturna plastična deformacija, konstitutivni model

\section{INTRODUCTION}

$12 \% \mathrm{Cr}$ ultra-supercritical rotor steel is a kind of high-strength and high-alloy steel that is difficult to deform. ${ }^{1,2}$ Extensive research work has been carried out on ultra-supercritical rotor materials and technology by many scholars. ${ }^{3-5}$ The manufacture of ultra-supercritical rotors usually includes ingot casting, cogging, drawing, heat treatment, machining and other processes. Especially in the forging process, the processing procedure may vary, and the technology is complex. In order to improve the quality of ultra-supercritical rotor steel, the thermal-deformation behavior and constitutive model of the $12 \% \mathrm{Cr}$ steel need to be studied systematically. It is necessary to study the high-temperature plastic-deformation behavior and the constitutive model of the $12 \% \mathrm{Cr}$ steel to optimize the production process.

*Corresponding author's e-mail:

jianshliu@126.com (Jiansheng Liu)
The plastic-deformation behavior and constitutive model of the materials have been studied by scholars internationally. P. Ludwik ${ }^{6}$ was the first to propose a flow-stress model for the materials under plastic deformation, which included the effects of the yield stress and strain on the stress. Voce proposed a constitutive model, which mainly considered the effects of the yield stress, saturation stress, true strain and relaxation strain on the flow stress. ${ }^{7}$ Fields and Bachofen suggested that the strain rate should also be an important parameter in the constitutive model. ${ }^{8}$ Based on the comprehensive effect of the temperature and strain rate on the microstructure evolution, Sellars et al. proposed a mathematical sine hyperbolic model. ${ }^{9}, 10$ U. F. Kocks et al. ${ }^{11-12}$ established constitutive models of work-hardening and dynamic-recovery phase based on the dislocation-density equation, namely a KM and EM dislocation-equation stress model. G. R. Johnson and W. H. Cook ${ }^{13}$ proposed a flow-stress model based on different deformation temperatures, 
strains and strain rates. F. J. Zerilli and R. W. Armstrong established a constitutive model, which considered the effects of strain hardening, strain-rate hardening and thermal softening on the flow behavior of a metal. ${ }^{14} \mathrm{Y}$. V. R. K. Prasad used a neural network to predict the flow-stress curve of medium-carbon steel, and the results showed that the neural-network model had a good predictive effect. ${ }^{15}$ Y. C. Lin et al. ${ }^{16}$ built a strain-compensation model for the 42CrMo steel based on the Sellars model. ${ }^{16}$ Laasraoui and Jonas studied the deformation behavior of low-carbon steel through a single-channel hot-compression test and established a two-stage physically based constitutive model of work-hardening/dynamic-recovery stage and dynamic-recrystallization stage based on an EM dislocation-equation stress model and dynamic-recrystallization dynamics model, respectively. ${ }^{17,18}$ F. Chen et al. ${ }^{19}$ studied the high-temperature flow law of typical large forging materials and established a two-stage high-temperature physically-based constitutive model of the $30 \mathrm{Cr} 2 \mathrm{Ni} 4 \mathrm{MoV}$ steel. ${ }^{19}$

Our predecessors did a lot of research on constitutive models, and the physically-based constitutive model, based on microscopic mechanisms was recognized by many scholars both in terms of the theoretical basis and model accuracy. However, the constitutive model of the as-cast $12 \% \mathrm{Cr}$ ultra-supercritical rotor steel is rarely studied. Based on the isothermal uniaxial compression test, the flow-stress curve of the as-cast $12 \% \mathrm{Cr}$ steel was obtained. By analyzing the effects of different deformation parameters on the deformation behavior of steel, the physically-based constitutive model was established and modified. The modified model improves the accuracy of the traditional physically-based constitutive model. It is useful for the optimization of the ultra-supercritical rotary-forging process.

\section{EXPERIMENTAL PART}

The material used for the test is the as-cast $12 \% \mathrm{Cr}$ ultra-supercritical rotor steel, whose chemical composition is shown in Table 1. The sample was taken from a $12 \% \mathrm{Cr}$ ingot. The test sample was a cylinder with 8

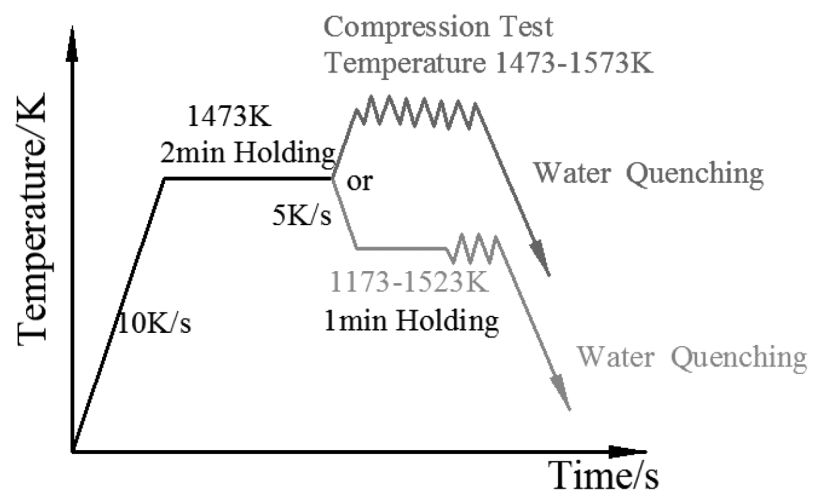

Figure 1: Schematic presentation of hot-deformation tests for the as-cast $12 \% \mathrm{Cr}$ steel $\mathrm{mm}$ in diameter and $12 \mathrm{~mm}$ in height. In order to study the thermal-deformation behavior of the $12 \% \mathrm{Cr}$ steel, in accordance with the hot-compression diagram in Figure 1, a Gleeble-1500D thermal/force simulation test machine was used for the uniaxial isothermal compression test. During the test, the sample was heated to $1473 \mathrm{~K}$ at a rate of $10 \mathrm{Ks}^{-1}$ and kept at this temperature for $2 \mathrm{~min}$. The sample was then heated or cooled to the deformation temperature at a rate of $5 \mathrm{Ks}^{-1}$ and kept at this temperature for $1 \mathrm{~min}$ to eliminate the temperature gradient. Next, the sample was compressed to a true strain of 0.7 . The temperature ranged from $1173 \mathrm{~K}$ to $1573 \mathrm{~K}$, with an interval of $50 \mathrm{~K}$. The strain rates were $(0.001,0.01,0.1$ and 1$) \mathrm{s}^{-1}$.

Table 1: Chemical composition of the as-cast $12 \% \mathrm{Cr}$ steel $(w / \%)$

\begin{tabular}{|c|c|c|c|c|c|c|c|}
\hline $\mathrm{C}$ & $\mathrm{Cr}$ & $\mathrm{Si}$ & $\mathrm{S}$ & $\mathrm{P}$ & $\mathrm{Mn}$ & $\mathrm{Ni}$ & $\mathrm{Mo}$ \\
\hline 0.109 & 11.193 & 0.06 & 0.0041 & 0.038 & 0.52 & 0.768 & 1.22 \\
\hline
\end{tabular}

\section{RESULTS AND DISCUSSION}

\subsection{Influence of deformation parameters on the flow-stress curve}

Figure 2 shows the flow-stress curves of the as-cast $12 \% \mathrm{Cr}$ steel at different temperatures and strain rates.
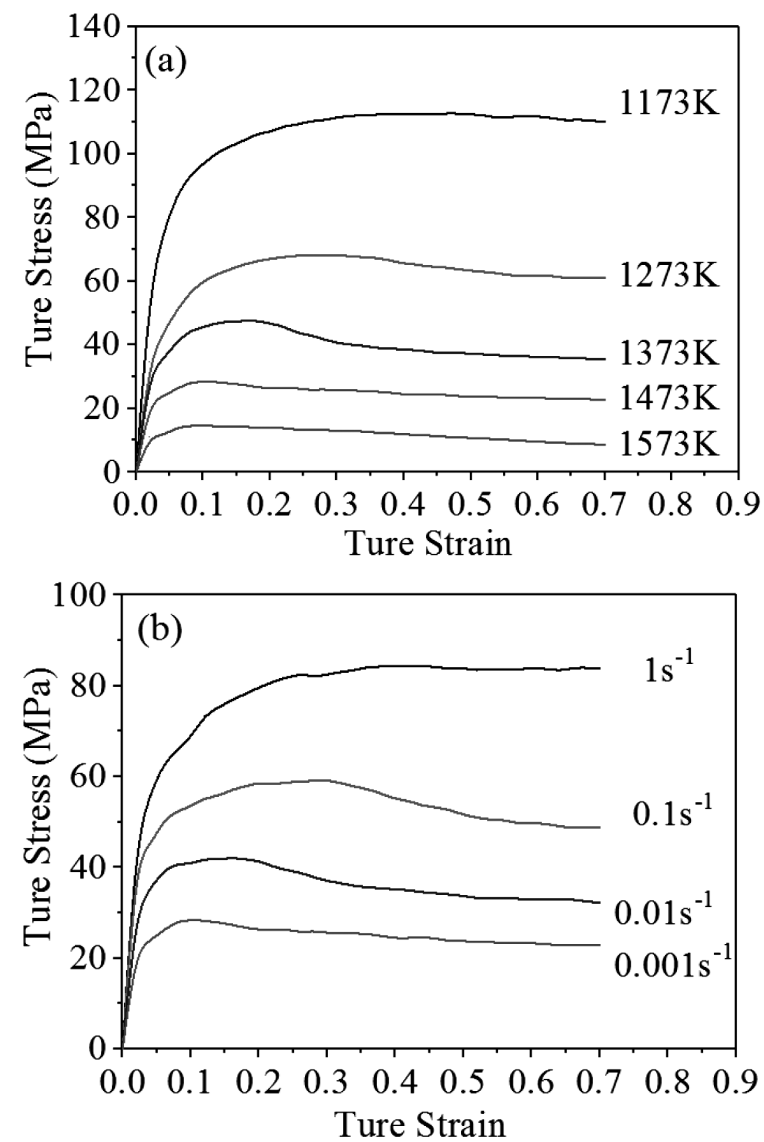

Figure 2: True-stress curves for different temperatures and strain rates: a) $0.001 \mathrm{~s}^{-1}$; b) $1437 \mathrm{~K}$ 
As shown in Figure 2a, under the same strain rate, the peak stress reaches the minimum when the temperature is $1573 \mathrm{~K}$. The peak stress decreases with the rise in the temperature. It can be seen from the figure that the temperature has a significant effect on the flow stress. Therefore, the flow stress decreases obviously with the increase in the deformation temperature. This is because the higher the deformation temperature, the smaller is the bonding force among the metal atoms so that the vacancy diffusion, dislocation climbing and crossed-slip resistance are reduced, and the number of dynamic-recrystallization nuclei is lower. At the same time, the metal may, at higher temperatures, also develop a new slip system, which can make plastic deformation easy, resulting in a stress reduction. In addition, a higher temperature reduces the activation energy required for the dynamic recovery and dynamic recrystallization of austenite, making the dynamic recovery and dynamic recrystallization more likely to occur. As softening mechanisms, they can eliminate work hardening, reducing the flow stress. Besides, at a higher deformation temperature, dynamic softening requires less deformation.

As shown in Figure 2b, at the same temperature, when the strain rate is $0.001 \mathrm{~s}^{-1}$, the peak stress is the lowest, while the peak stress increases with the strain rate. This is because under a high deformation rate, the slipping of dislocation can be hindered by the increase in the dislocation density. The occurrence of dynamic recrystallization is limited by the nucleation time. So, larger deformation is required for a full recrystallization and a large flow stress.

\subsection{Establishment of the Arrhenius equation}

The deformation of metal at high temperatures is a process of thermal activation. The activation energy of thermal deformation is a physical quantity, which represents the difficulty of thermal deformation. During hot deformation, the influence of the Zener-Hollomon $(Z)$ parameters, deformation temperature and strain rate on the flow stress of the materials can be expressed with the Arrhenius equation proposed by Zener and Hollomon:20

$$
\dot{\varepsilon} \exp \left(\frac{Q}{R T}\right)=\left\{\begin{array}{l}
A_{1} \sigma^{n^{\prime}}(\alpha \sigma<0.8) \\
A_{2} \exp (\beta \sigma)(\alpha \sigma>1.2) \\
A[\sinh (\alpha \sigma)]^{n} \text { (for all) }
\end{array}\right.
$$

where $\dot{\varepsilon}$ is the strain rate $\left(\mathrm{s}^{-1}\right), Q$ is the thermal deformation activation energy $(\mathrm{J} / \mathrm{mol}), R$ is the universal gas constant $(8.314 \mathrm{~J} /(\mathrm{mol} \cdot \mathrm{K})), T$ is the absolute temperature $(\mathrm{K}), \sigma$ is the flow stress $(\mathrm{MPa})$, while $\mathrm{A}_{1}, \mathrm{~A}_{2}, \mathrm{~A}, \alpha$, $\beta$, n' and $\mathrm{n}$ are the material constants. Power functions apply to low-stress levels, while exponential functions describe high-stress levels. ${ }^{21}$ The hyperbolic sine function used in all the cases is obtained by combining the two functions. By taking the natural logarithms of both
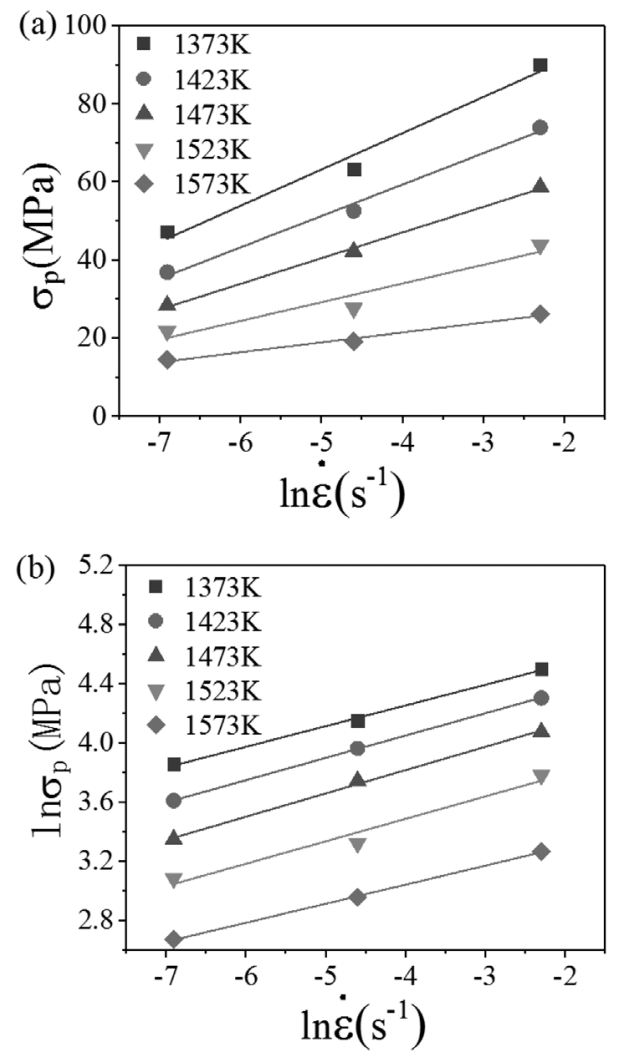

Figure 3: Relationships with the peak stress and strain rate: a) $\ln \varepsilon-$ $\sigma p ;$ (b) $\ln \varepsilon-\sigma p$
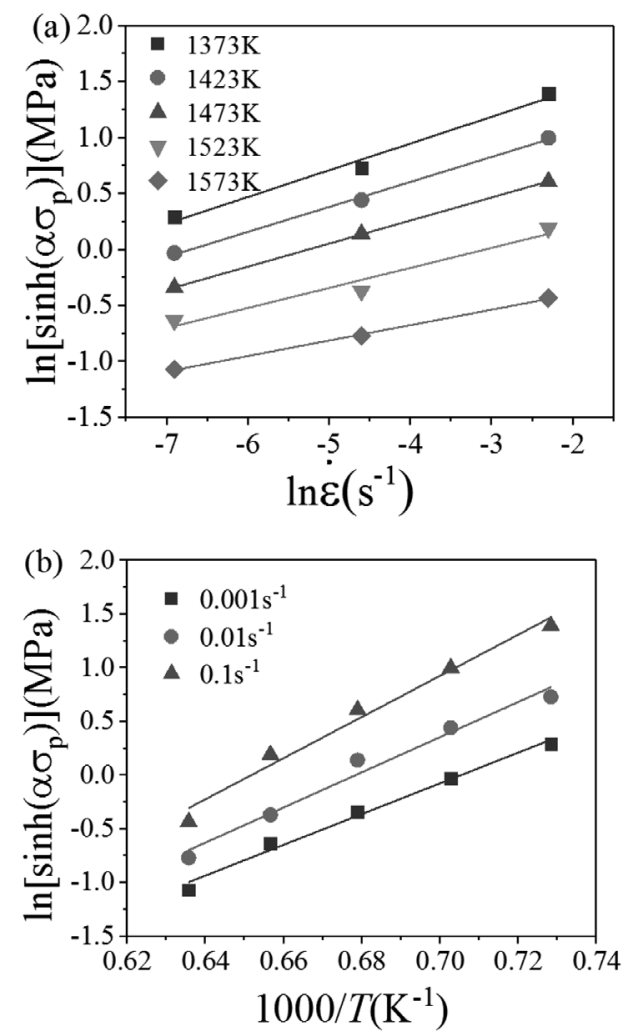

Figure 4: Relationships between $\ln \left[\sinh \left(\alpha \sigma_{\mathrm{p}}\right)\right]$ and $\ln \dot{\varepsilon}$ or $1000 / T$ : a) $\left.\ln \left[\sinh \left(\alpha \sigma_{\mathrm{p}}\right)\right]-\ln \dot{\varepsilon} ; \mathrm{b}\right) \ln \left[\sinh \left(\alpha \sigma_{\mathrm{p}}\right)\right]-1000 / T_{\ln \sinh \alpha \sigma \mathrm{p}}$ 
sides of Equation (2), the following expression can be obtained:

$$
\ln \dot{\varepsilon}+\frac{Q}{R T}=\left\{\begin{array}{l}
\ln A_{1}+n^{\prime} \ln \sigma(\alpha \sigma<0.8) \\
\ln A_{2}+\beta \sigma(\alpha \sigma>1.2) \\
\ln A+n \ln [\sinh (\alpha \sigma)] \text { (for all) }
\end{array}\right.
$$

The thermal deformation activation energy is characterized by the corresponding peak stress $\sigma_{\mathrm{p}}$. The peak stress is obtained with the flow-stress curve. The values of $\beta, n$ ', $n$ and $Q$ are obtained with the linear fitting of the experimental data. And they can be calculated with the average slope of the oblique lines from Figures $\mathbf{3}$ and 4. The relationship between $\ln \dot{\varepsilon}$ and $\sigma_{\mathrm{p}}$ at a constant temperature is shown in Figure 3a. The relationship between and $\ln \sigma_{\mathrm{p}}$ is shown in Figure 3b. In general, the value of $\alpha$ is determined by $\beta$ and $n$ ' that is $\alpha=\beta / n$ '. The relationships between $\ln \dot{\varepsilon}, \ln \left[\sinh \left(\alpha \sigma_{\mathrm{p}}\right)\right]$ and 1000/T are shown in Figure 4. According to the above procedure, the values of $A, \alpha, \beta, n^{\prime}, n$ and $Q$ are $6.0569 \times 10^{17}$, $0.0233,0.1600,6.8659,3.2237$ and $451765.36 \mathrm{~J} \cdot \mathrm{mol}^{-1}$, respectively. Therefore, the parameter $Z$ can be expressed with Equation (3) and the peak stress can be expressed with Equation (4) after the transformation.

$$
\begin{aligned}
Z & =\dot{\varepsilon} \exp \left(\frac{451765.36}{R T}\right)= \\
= & 6.0569 \times 10^{17}\left[\sinh \left(0.233 \sigma_{\mathrm{p}}\right)\right]^{3.2237} \\
\sigma_{\mathrm{p}} & =42.92 \sinh ^{-1}\left(3.2817 \times 10^{-5} Z^{0.3102}\right)
\end{aligned}
$$

\subsection{Modelling of the work hardening/dynamic recovery stage}

The physically based constitutive model based on the microstructure evolution takes the dislocation changes during hot deformation into account and can accurately predict the flow stress under different conditions. During the work hardening/dynamic recovery stage, the hardening and softening mechanisms are work hardening $(W H)$ and dynamic recovery (DRV), respectively. Since the variation in the dislocation density is affected by both work hardening and dynamic recovery, the evolution model of dislocation density can be expressed with Equation (5): $:^{22}$

$$
\frac{\mathrm{d} \rho}{\mathrm{d} \varepsilon}=k_{1} \sqrt{\rho}-k_{2} \rho
$$

where $\mathrm{d} \rho / \mathrm{d} \varepsilon$ represents the change in the rate of dislocation density caused by the strain, $\rho$ represents the dislocation density, $k_{1}$ is the work-hardening coefficient and $k_{2}$ is the dynamic-recovery coefficient.

During the thermal-deformation process, the relationship between the flow stress of materials and dislocation density can be expressed as: ${ }^{11}$

$$
\sigma_{\mathrm{wH}}=\alpha \mu b \sqrt{\rho}
$$

where $\alpha$ is the material constant, $\mu$ is the shear modulus and $b$ is the Burgers vector.

The derivative of Equation (6) can be obtained as follows:

$$
\frac{\mathrm{d} \sigma_{\mathrm{WH}}}{\mathrm{d} \rho}=\frac{\alpha \mu b}{2 \sqrt{\rho}}
$$

Synthesizing Equations (5) and (7), the work-hardening rate can be expressed as:

$$
\begin{aligned}
& \theta=\frac{\mathrm{d} \sigma_{\mathrm{WH}}}{\mathrm{d} \varepsilon}=\frac{\mathrm{d} \sigma}{\mathrm{d} \varepsilon} \cdot \frac{\mathrm{d} \sigma_{\mathrm{WH}}}{\mathrm{d} \rho}= \\
& =\frac{\alpha \mu b k_{1}-\alpha \mu b k_{2} \sqrt{\rho}}{2}=\frac{\alpha \mu b k_{1}-k_{2} \sigma_{\mathrm{WH}}}{2}
\end{aligned}
$$

When $\theta=0$, then

$$
\sigma_{\text {sat }}=\frac{\alpha \mu b k_{1}}{k_{2}}
$$

Where $\sigma_{\text {sat }}$ denotes the saturation stress. According to Equation (8), it can be obtained that:

$$
\mathrm{d} \varepsilon=\frac{\mathrm{d} \sigma_{\mathrm{wH}}}{\theta}=\frac{2 \mathrm{~d} \sigma_{\mathrm{wH}}}{\alpha \mu b k_{1}-k_{2} \sigma_{\mathrm{wH}}}
$$

By integrating Equation (10), it can be obtained that:

$$
\varepsilon=-\frac{2}{k_{2}} \ln \left(\alpha \mu b k_{1}-k_{2} \sigma_{\mathrm{wH}}\right)+C_{1}
$$

With an equivalent transformation, we obtain the following:

$$
\alpha \mu b k_{1}-k_{2} \sigma_{\mathrm{wH}}=C_{2} \exp \left(-\frac{k_{2}}{2} \varepsilon\right)
$$

When $=0$, then $\sigma=0$ and substitute $\sigma=0$ in Equation (12), we obtain:

$$
C_{2}=\alpha \mu b k_{1}
$$

Substituting Equations (9) and (13) into Equation (12), the work hardening/dynamic recovery model can be obtained:

$$
\begin{aligned}
& \sigma_{\mathrm{wH}}=\frac{\alpha \mu b k_{1}-\alpha \mu b k_{1} \exp \left(-\frac{k_{2}}{2} \varepsilon\right)}{k_{2}}= \\
& =\sigma_{\text {sat }}-\sigma_{\text {sat }} \exp \left(-\frac{k_{2}}{2} \varepsilon\right)
\end{aligned}
$$

When building a material constitutive model, the work-hardening rate $\theta$ and flow stress $\sigma$ curve can indirectly reveal the evolution of the microstructure during hot deformation to determine the value of the characteristic stress. The work-hardening schematic diagram is shown in Figure 5. When the material begins to deform, the work-hardening rate decreases rapidly with the increase in the stress. When the flow stress reaches the critical stress value $\sigma_{\mathrm{c}}$, material dynamic crystallization occurs. When the stress reaches the peak stress $\sigma_{\mathrm{p}}$, the 
$\theta$

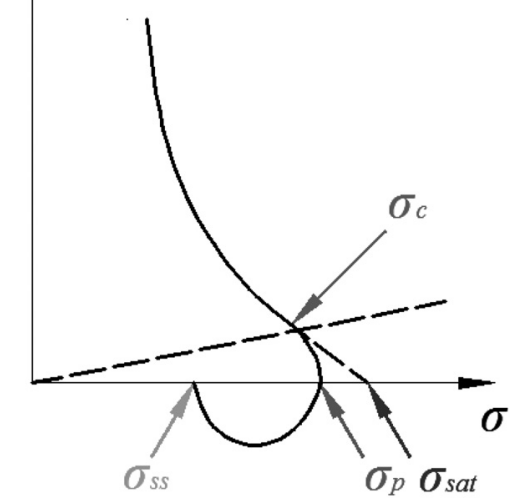

Figure 5: Relationship between the work-hardening rate and flow stress

work-hardening rate is 0 . With the increase in the dynamic-recrystallization fraction, the work-hardening rate is negative. When dynamic recrystallization, dynamic recovery and work hardening are balanced, the work-hardening rate becomes 0 again.

The saturation stress of the material can be obtained from the relationship diagram of the work-hardening rate and flow stress, and the dynamic-recovery coefficient $k_{2}$ can be calculated from Equation (14). Dynamic-response coefficient $k_{2}$ can usually be expressed with parameter $\mathrm{Z}$ and its mathematical relation is shown with Equation (15):

$$
k_{2}=C_{3} Z^{n_{1}}
$$

Based on the relationship between $\ln k_{2}$ and $\ln Z$ and the linear-regression method, coefficients $C_{3}$ and $n_{1}$ can be solved, and Equation (15) can be expressed as:

$$
k_{2}=456.0078 Z^{-0.06485}
$$

Peak stress $\sigma_{\mathrm{p}}$ on the stress/strain curve can be characterized with parameter $\mathrm{Z}$, while saturation stress $\sigma_{\text {sat }}$ can be characterized with peak stress $\sigma_{\mathrm{p}}$. In the form of linear regression, the relationship between the saturation stress and peak stress can be expressed as:

$$
\sigma_{\text {sat }}=1.08 \sigma_{\mathrm{p}}
$$

To sum up, the constitutive model for $12 \% \mathrm{Cr}$ ultrasupercritical rotor steel during work hardening/dynamic recovery period can be represented with the following model:

$$
\left\{\begin{array}{l}
\sigma_{\mathrm{wH}}=\sigma_{\text {sat }}-\sigma_{\text {sat }} \exp \left(-k_{2} \varepsilon / 2\right) \\
\mathrm{Z}=\dot{\varepsilon} \exp (451765.36 / R T) \\
k_{2}=456.0078 Z^{-0.06485} \\
\sigma_{\text {sat }}=1.08 \sigma_{\mathrm{p}} \\
\sigma_{\mathrm{p}}=42.92 \sinh ^{-1}\left(3.2817 \times 10^{-5} Z^{0.3102}\right)
\end{array}\right.
$$

\subsection{Modeling of the dynamic-recrystallization stage}

In general, during the dynamic recrystallization stage, the dynamic-recrystallization kinetics can be expressed with the Avrami equation: ${ }^{23}$

$$
X_{\mathrm{d}}=1-\exp \left[-\beta_{\mathrm{d}}\left(\frac{\varepsilon-\varepsilon_{\mathrm{c}}}{\varepsilon_{\mathrm{p}}}\right)\right]\left(\varepsilon \geq \varepsilon_{\mathrm{c}}\right)
$$

where $X_{\mathrm{d}}$ is the dynamic-recrystallization percentage, $\beta_{\mathrm{d}}$ and $k_{\mathrm{d}}$ are the material constants and $\varepsilon_{\mathrm{c}}$ is the critical strain. Dynamic-recrystallization percentage can also be expressed as: ${ }^{24}$

$$
X_{\mathrm{d}}=\frac{\sigma_{\mathrm{wH}}-\sigma}{\sigma_{\mathrm{sat}}-\sigma_{\mathrm{ss}}}\left(\varepsilon \geq \varepsilon_{\mathrm{c}}\right)
$$

where $\sigma_{\mathrm{WH}}$ is the flow stress in the period of work hardening and dynamic recovery, $\sigma_{\mathrm{ss}}$ is the steady-state stress and $\sigma_{\text {sat }}$ is the saturation stress. Combined with Equations (19-20), the flow stress in the dynamicrecrystallization period can be expressed with the following equation:

$\sigma=\sigma_{\mathrm{wH}}-\left(\sigma_{\mathrm{sat}}-\sigma_{\mathrm{ss}}\right)\left\{1-\exp \left[-\beta_{\mathrm{d}}\left(\frac{\varepsilon-\varepsilon_{\mathrm{c}}}{\varepsilon_{\mathrm{p}}}\right)^{k_{d}}\right]\right\}\left(\varepsilon \geq \varepsilon_{\mathrm{c}}\right)$

According to Equation (21), $\sigma_{\mathrm{ss}}, \varepsilon_{\mathrm{p}}, \varepsilon_{\mathrm{c}}, \beta_{\mathrm{d}}$ and $k_{\mathrm{d}}$ need to be determined. Peak stress $\varepsilon_{\mathrm{p}}$ can be obtained from the stress/true strain curve and peak stress can be expressed in the exponential form of the Zener-Hollomon parameter:

$$
\varepsilon_{\mathrm{p}}=k_{3} Z^{m}
$$

where $k_{3}$ and $m$ are material constants. The peak stress can be expressed with the function of parameter $Z$ as follows:

$$
\varepsilon_{\mathrm{p}}=0.0008783 Z^{0.1593}
$$

Generally, dynamic recrystallization occurs before the flow stress reaches the peak stress. There is a complex functional relationship between the critical strain and deformation temperature, strain rate, temperature and recrystallization thermal-activation energy. Some scholars believe that the critical strain of a material and the peak strain satisfy the mathematical relationship shown in Equation (24): 25,26

$$
\varepsilon_{\mathrm{c}}=0.8 \varepsilon_{\mathrm{p}}
$$

In addition, steady-state stress $\sigma_{\mathrm{ss}}$ can be obtained from the stress/strain curve. The relationship between the steady-state stress and the peak stress can be expressed as:

$$
\sigma_{\mathrm{ss}}=0.9551 \sigma_{\mathrm{p}}
$$

In order to obtain the values of $k_{\mathrm{d}}$ and $\beta_{\mathrm{d}}$, Equation (19) can be rewritten as:

$$
\ln \left[-\ln \left(1-X_{\mathrm{d}}\right)\right]=\ln \beta_{\mathrm{d}}+k_{\mathrm{d}} \ln \left(\frac{\varepsilon-\varepsilon_{\mathrm{c}}}{\varepsilon_{\mathrm{p}}}\right)
$$


X. ZHANG et al.: HOT-DEFORMATION BEHAVIOR AND A MODIFIED PHYSICALLY BASED CONSTITUTIVE MODEL ...
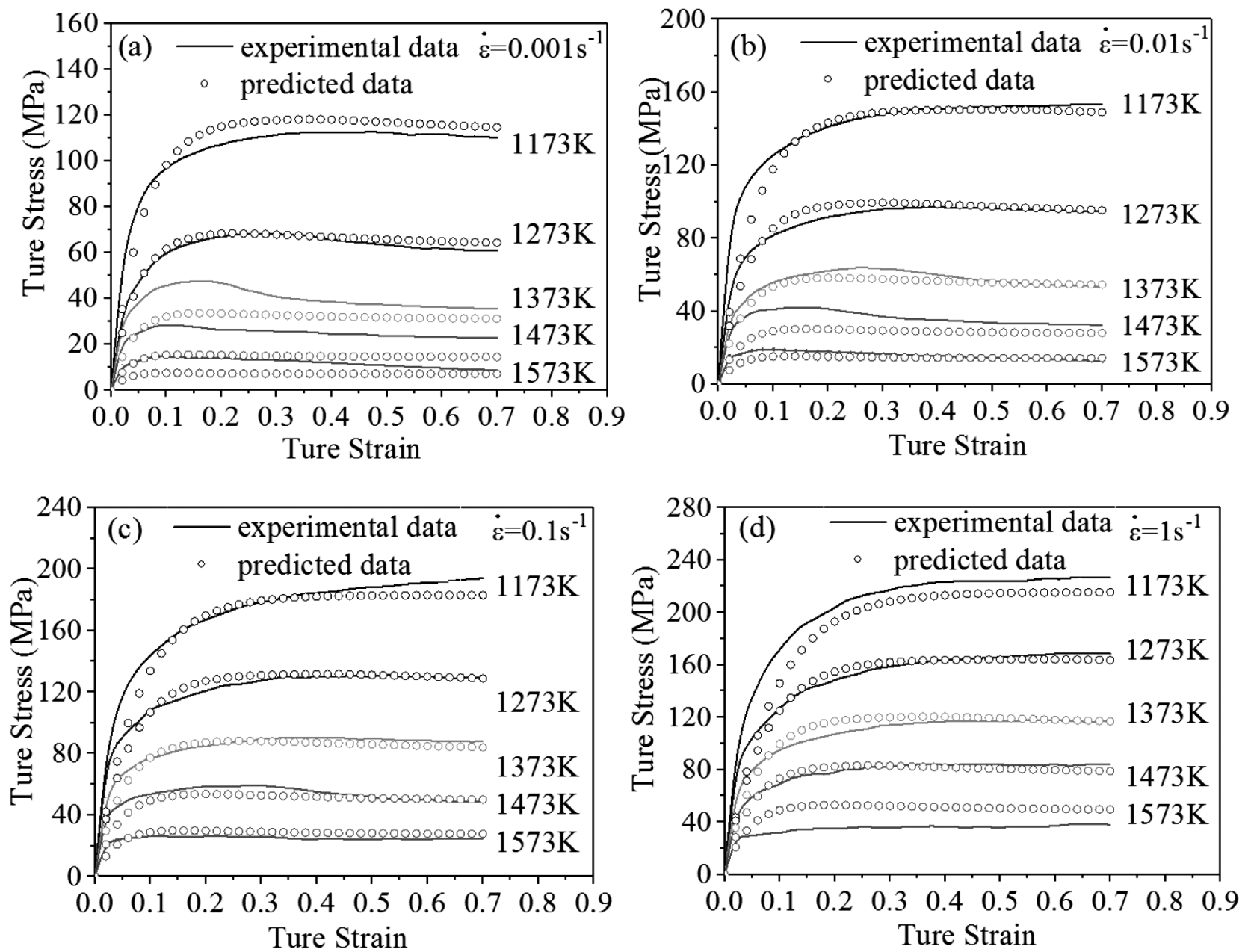

Figure 6: Comparison between the experimental and predicted flow stress at different strains for strain rates of: a) $0.001 \mathrm{~s}^{-1}$, b) $0.01 \mathrm{~s}^{-1}$, c) $\left.0.1 \mathrm{~s}^{-1}, \mathrm{~d}\right) 1 \mathrm{~s}^{-1}$

According to Equation (26), parameters $k_{\mathrm{d}}$ and $\beta_{\mathrm{d}}$, can be calculated with linear regression. After the mathematical calculation, $k_{\mathrm{d}}=1.13$ and $\beta_{\mathrm{d}}=0.58$.

Therefore, the constitutive model of the $12 \% \mathrm{Cr}$ alloy steel during dynamic recrystallization can be expressed as follows:

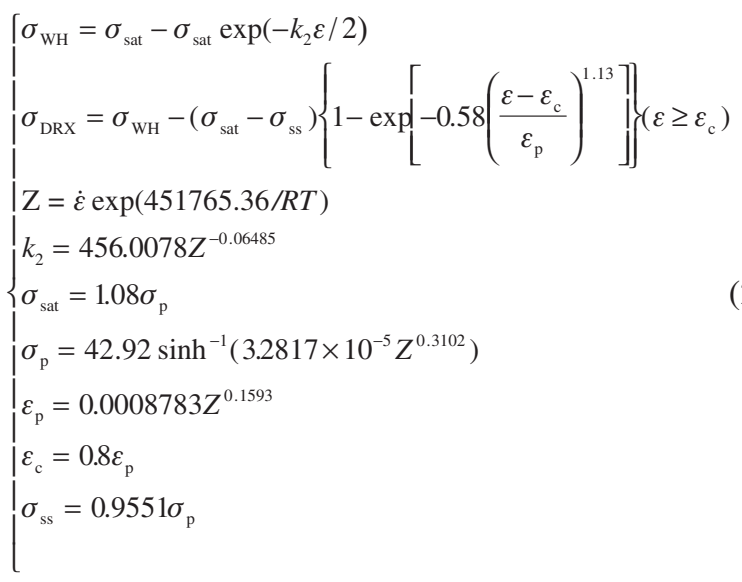

\subsection{Model validation}

Based on Equations (18) and (27), the comparison between experimental data and predicted data of the constitutive model under different conditions is shown in Figure 6. As can be seen, the constitutive model can accurately predict the flow stress. In addition, in order to compare the results obtained from the constitutive model with the experimental data more directly, the reliability of the constitutive model is evaluated according to Equations (28-29)

$$
\begin{gathered}
A A R E=\frac{1}{n} \sum_{i=1}^{n}\left|\frac{\sigma_{\mathrm{e}}-\sigma_{\mathrm{p}}}{\sigma_{\mathrm{e}}}\right| \times 100 \% \\
R M S E=\sqrt{\frac{1}{n} \sum_{i=1}^{n}\left(\sigma_{\mathrm{e}}-\sigma_{\mathrm{p}}\right)^{2}}
\end{gathered}
$$

where $\sigma_{\mathrm{e}}$ is the experimental flow stress, $\sigma_{\mathrm{p}}$ is the predicted flow stress and $n$ is the total number of data. The results show that the average absolute relative error $(A A R E)$ is $14.6 \%$ and the root mean square error (RMSE) is $19.3 \mathrm{MPa}$. This indicates that the constitutive 
model can effectively predict the flow behavior of the $12 \% \mathrm{Cr}$ steel.

\subsection{Model modification}

The physically based constitutive model established on the basis of the mechanism of microstructure evolution has high accuracy, but it can be seen from this paper and other scholars' papers that the error of the predicted value of this model at the initial stage of deformation is relatively large. ${ }^{27,28}$ It can be seen that the error of the model mainly appears in the dynamic-recovery stage. The main reason for this error is the fact that the constitutive model is established on the premise that the dynamic-recovery coefficient is related to parameter Z. So, the model is based on the presumption that the dynamic-recovery coefficient $k_{2}$ is only related to the deformation temperature and strain rate. However, according to Equation (14), it can be seen that the dynamic-recovery coefficient is not only related to the deformation temperature and strain rate but also to the strain; this is the reason for the large error of the constitutive model at the initial stage of deformation. As a result, the model is modified in this study.

According to Equation (14), the relationship between the dynamic-recovery coefficient and strain under different deformation conditions can be obtained. After smoothing, the relationship curve for the dynamic-recovery coefficient $k_{2}$ and strain is obtained, as shown in Figure 7. According to the curve morphology from this figure, dynamic-recovery coefficient $k_{2}$ can be modified as follows:

$$
k_{2}=K_{1} \times 10^{K_{2} \varepsilon}+K_{3}
$$

where $K_{1}, K_{2}, K_{3}$ are the model coefficients.

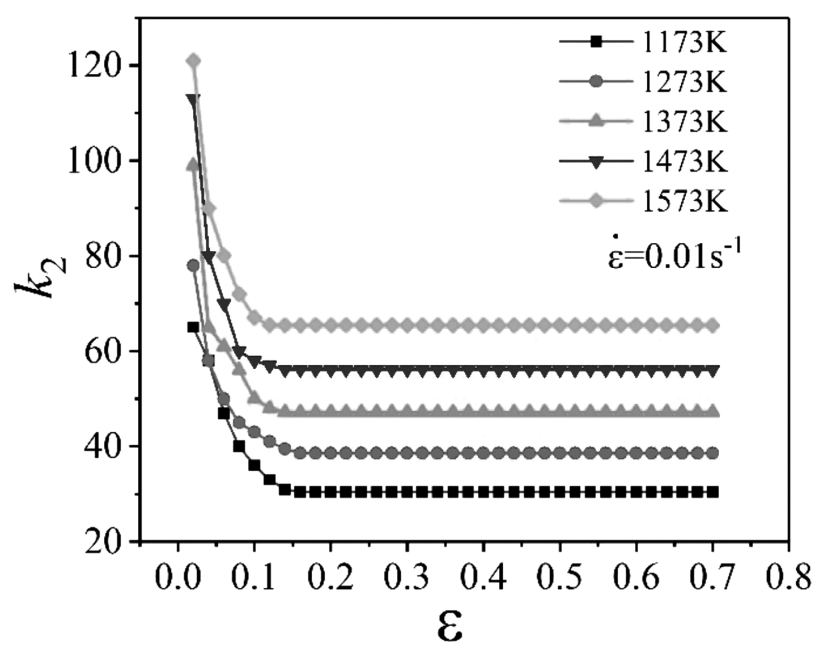

Figure 7: Relationship between $k_{2}$ and the strain
The mathematic relation of dynamic-recovery coefficient $k_{2}$ and strain was fitted with a custom nonlinear function in the Origin software to obtain model coefficients under different conditions. The relationships between coefficients $K_{1}, K_{2}$ and $\ln Z$ are shown in Figure 8. Through linear fitting, we can obtain:

$$
\begin{gathered}
K_{1}=-11.00 \ln Z+b \\
K_{2}=0.7294 \ln Z-45.6575
\end{gathered}
$$

where $b$ is the intercept of the fitted line. The intercept is obviously related to the strain rate, so it can be obtained using linear fitting with the strain rate, therefore:

$$
K_{1}=-11.00 \ln Z+26.89 \ln \dot{\varepsilon}+603.34
$$

$K_{3}$ is the dynamic-recovery coefficient in the steady-state stage. According to the characteristics of the function of Equation (30), the value of $K_{3}$ is consistent with the dynamic-recovery coefficient before the modification, namely:

$$
K_{3}=-456.0078 Z^{-0.06485}
$$
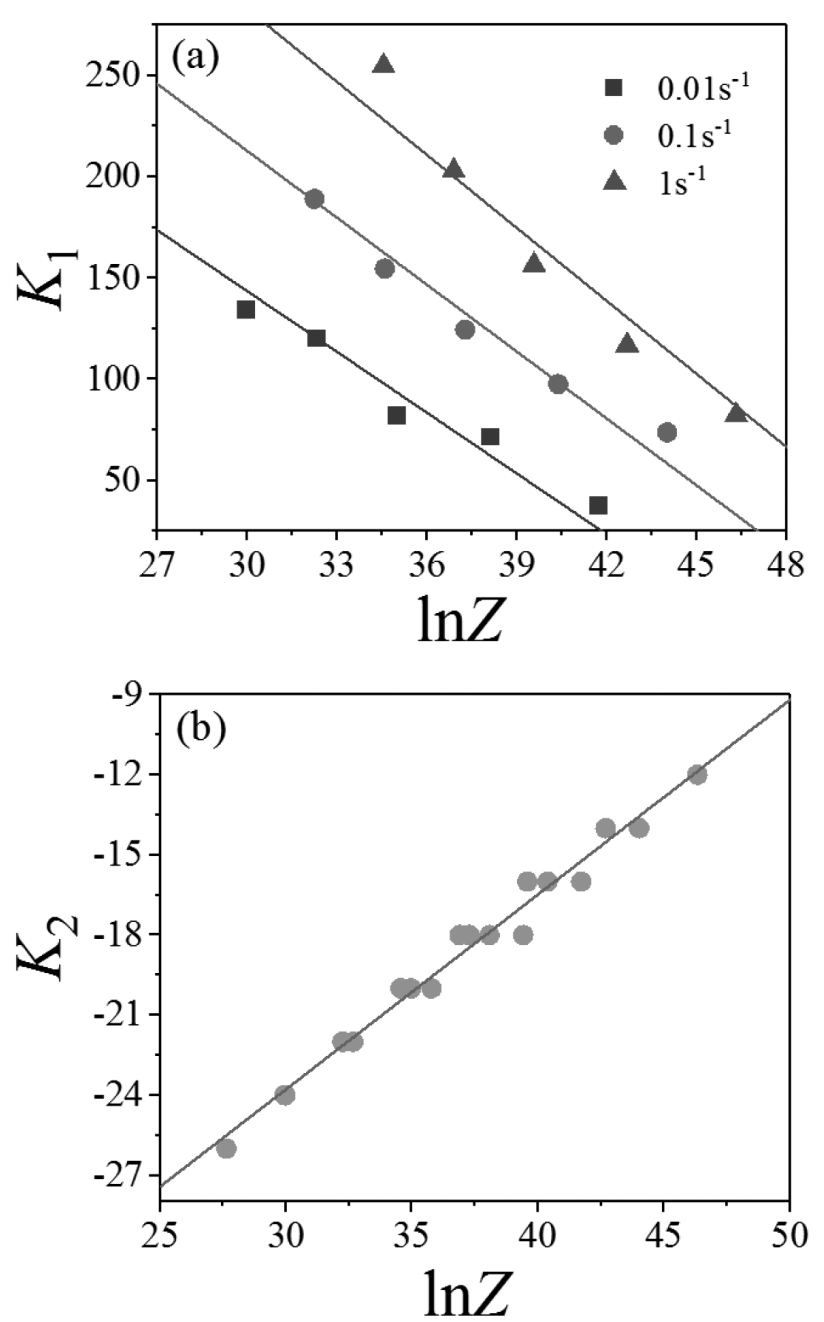

Figure 8: Relationship between $\ln Z$ and $K_{1}, K_{2}$ 
X. ZHANG et al.: HOT-DEFORMATION BEHAVIOR AND A MODIFIED PHYSICALLY BASED CONSTITUTIVE MODEL ...

To sum up, the modified physically based constitutive model of the as-cast $12 \% \mathrm{Cr}$ steel is as follows:

$\left\{\begin{array}{l}\sigma=\sigma_{\mathrm{WH}}\left(\varepsilon<\varepsilon_{\mathrm{c}}\right) \\ \sigma=\sigma_{\mathrm{DRX}}\left(\varepsilon \geq \varepsilon_{\mathrm{c}}\right) \\ \sigma_{\mathrm{WH}}=\sigma_{\mathrm{sat}}-\sigma_{\mathrm{sat}} \exp \left(-k_{2} \varepsilon / 2\right) \\ \sigma_{\mathrm{DRX}}=\sigma_{\mathrm{WH}}-\left(\sigma_{\mathrm{sat}}-\sigma_{\mathrm{ss}}\right)\left\{1-\exp \left[-0.58\left(\frac{\varepsilon-\varepsilon_{\mathrm{c}}}{\varepsilon_{\mathrm{p}}}\right)^{1.13}\right]\right\} \\ \mathrm{Z}=\dot{\varepsilon} \exp (451765.36 / R T) \\ k_{2}=456.0078 Z^{-0.06485} \\ K_{1}=-11.00 \ln Z+26.89 \ln \dot{\varepsilon}+603.34 \\ K_{2}=0.7294 \ln Z-45.6575 \\ K_{3}=456.0078 Z^{-0.06485} \\ \sigma_{\mathrm{sat}}=1.08 \sigma_{\mathrm{p}} \\ \sigma_{\mathrm{p}}=42.92 \sinh ^{-1}\left(3.2817 \times 10^{-5} Z^{0.3102}\right) \\ \varepsilon_{\mathrm{p}}=0.0008783 Z^{0.1593} \\ \varepsilon_{\mathrm{c}}=0.8 \varepsilon_{\mathrm{p}} \\ \sigma_{\mathrm{ss}}=0.9551 \sigma_{\mathrm{p}}\end{array}\right.$
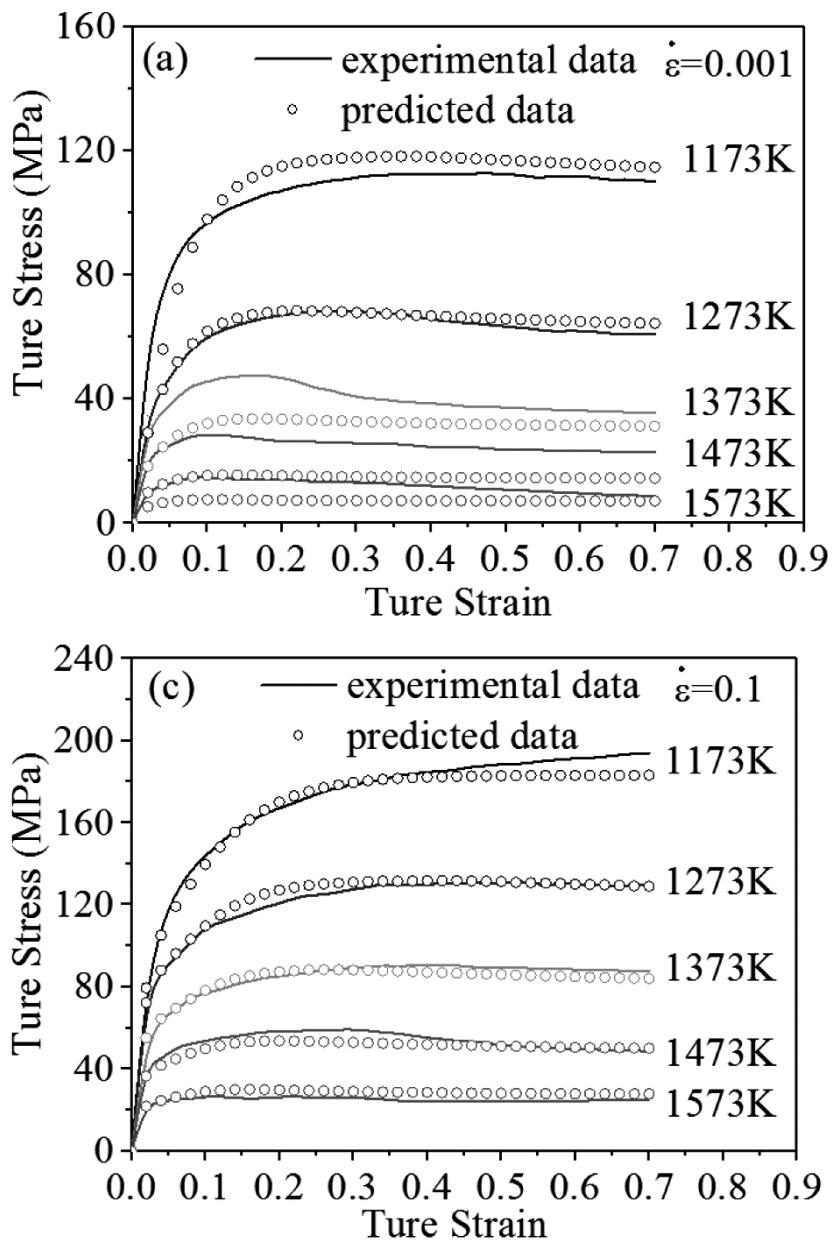

Based on Equation (35), the comparison between experimental data and predicted data is shown in Figure 9. After the error analysis, the average absolute relative error (AARE) is $12.2 \%$ and the root mean square error (RMSE) is 7.0 MPa. It can be seen that the modified constitutive model can further reduce its error, especially the root mean square error, which is reduced by about $63.7 \%$.

\section{CONCLUSIONS}

Based on a uniaxial isothermal compression test, the stress/strain curve of the as-cast $12 \% \mathrm{Cr}$ ultra-supercritical rotor steel was established. Through an in-depth analysis of the macroscopic flow-stress characteristics of this steel, a physically based constitutive model based on the microstructure mechanism was established. The main conclusions are as follows:

1) According to the Arrhenius equation, the basic thermodynamic parameters of the as-cast $12 \% \mathrm{Cr}$ ultra-supercritical rotor steel were calculated. And the activation energy of the thermal deformation of the steel is $451.765 \mathrm{~kJ} / \mathrm{mol}$.
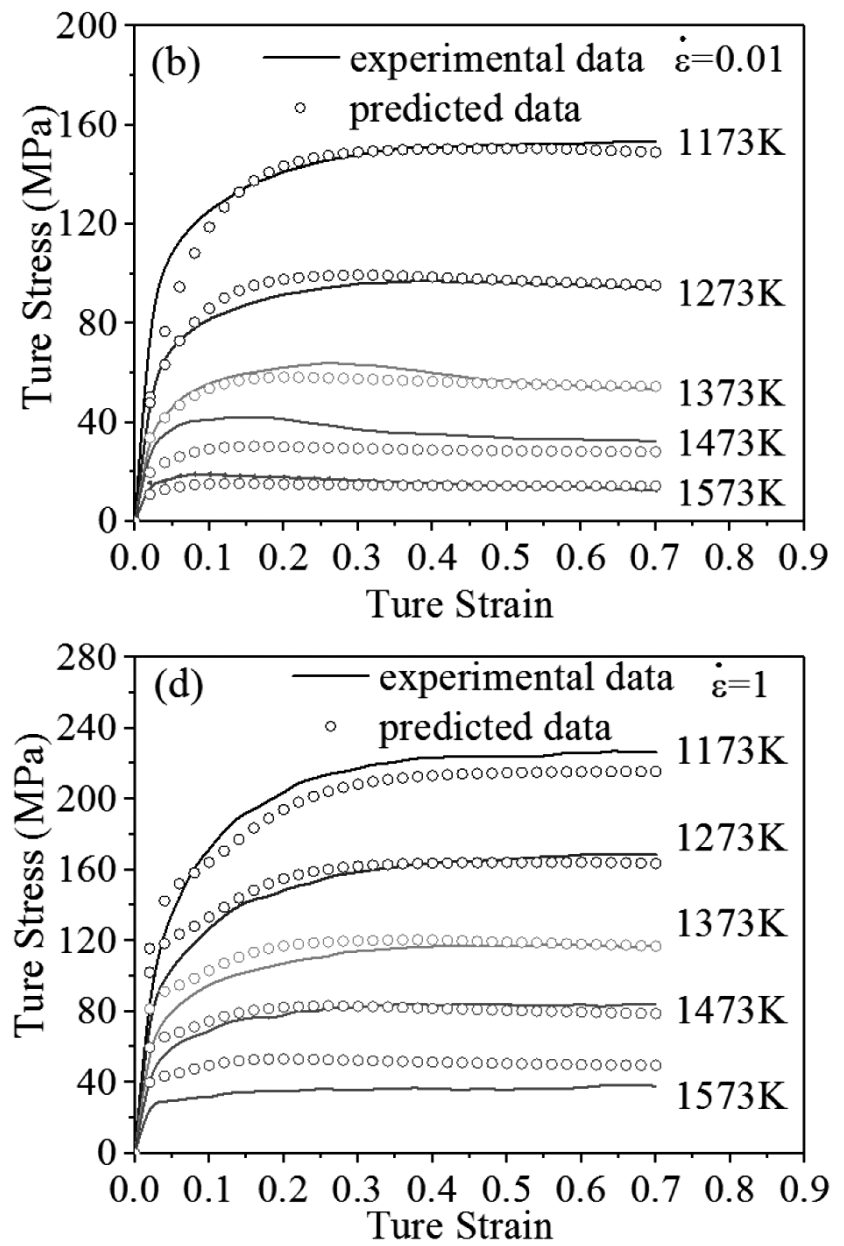

Figure 9: Comparison between the experimental and predicted flow stress at different strains for strain rates of:a) $0.001 \mathrm{~s}^{-1}$, b) $0.01 \mathrm{~s}^{-1}$, c) $\left.0.1 \mathrm{~s}^{-1}, \mathrm{~d}\right) 1 \mathrm{~s}^{-1}$ 


\section{ZHANG et al.: HOT-DEFORMATION BEHAVIOR AND A MODIFIED PHYSICALLY BASED CONSTITUTIVE MODEL ..}

2) There are two kinds of flow-stress curves for the as-cast $12 \% \mathrm{Cr}$ ultra-supercritical rotor steel, namely, the flow-stress curves of the work hardening/dynamic recovery and dynamic recrystallization. The softening mechanisms of the two flow-stress curves are different, including dynamic recovery and dynamic recrystallization.

3) Based on the two flow-stress curves of the $12 \%$ Cr steel, a two-stage physically based constitutive model was established and the model was modified. The average absolute relative error (AARE) of the modified model is $12.2 \%$ and the root-mean-square error $(R M S E)$ is 7.0 $\mathrm{MPa}$. The accuracy of the model is improved compared with the physically based constitutive model before the modification.

\section{Acknowledgments}

The work was sponsored by the National Natural Science Foundation of China (51775361), the Shanghai Dianji University, and the Shanghai Research Center of Engineering Technology for Large Parts Thermal Manufacturing.

\section{REFERENCES}

${ }^{1}$ H. Gong, Z. Guo, J. Liu, Growth behavior of austenite grain of forged $12 \% \mathrm{Cr}$ ultra-supercritical rotor steel, Jinshu Rechuli/Heat Treatment of Metals, 42 (2017) 10, 215-219, doi:10.13251/ j.issn.0254-6051.2017.10.043

${ }^{2}$ Z. Ye, P. Wang, D. Li, et al., Effect of carbon and niobium on the microstructure and impact toughness of a high silicon $12 \% \mathrm{Cr}$ ferritic martensitic heat resistant steel, Materials Science and Engineering: A, 616 (2014), 12-19, doi:10.1016/j.msea.2014.07.087

${ }^{3}$ V. Lépingle, G. Louis, D. Petelot, et al., Steam Corrosion Resistance of New $12 \%$ Cr Ferritic Boiler Steels, Materials Science Forum, 461-464 (2004), 1039-1046, doi:10.4028/www.scientific.net/MSF. 461-464.1039

${ }^{4}$ E. Manilova, Examination of Minor Phases in Martensitic 12\% Cr-Mo-W-V Steel, Microscopy and Microanalysis, 12 (2006) 2, 1612-1613, doi:10.1017/S1431927606064786

${ }^{5}$ Y. Chen, F. Zhang, Q. Yan, et al., Microstructure characteristics of $12 \mathrm{Cr}$ ferritic/martensitic steels with various yttrium, Journal of Rare Earths, 37 (2019) 5, 547-554, doi:10.1016/j.jre.2018.08.013

${ }^{6}$ P. Ludwik, Elemente der Technologischen Mechanik, Springer, Berlin 1909, 57

${ }^{7}$ Y. C. Lin, X. M. Chen, A critical review of experimental results and constitutive descriptions for metals and alloys in hot working, Materials \& Design, 32 (2011) 4, 1733-1759, doi:10.1016/j.matdes.2010. 11.048

${ }^{8}$ R. P. Ferreira, E. S. Silva, C. C. F. Nascimento, et al., Thermomechanical Behavior Modeling of a Cr-Ni-Mo-Mn-N Austenitic Stainless Steel, Materials Sciences and Applications, 7 (2016) 12, 803-822, doi:10.4236/msa.2016.712062

${ }^{9}$ C. M. Sellars, W. J. McTegart, On the mechanism of hot deformation, Acta Metallurgica, 14 (1966) 9, 1136-1138, doi:10.1016/00016160(66)90207-0

${ }^{10}$ C. M. Sellars, Computer modeling of hot-working processes, Materials Science and Technology, 1 (1985) 4, 325-332, doi:10.1179/ mst.1985.1.4.325
${ }^{11}$ H. Merking, U. F. Kocks, Kinetics of flow and strain-hardening, Acta Metallurgica, 29 (1981) 11, 1865-1875, doi:10.1016/0001-6160(81) 90112-7

${ }^{12}$ Y. Estrin, H. Merking, A unified phenomenological description of work hardening and creep based on one-parameter model, Acta Metallurgica, 32 (1984) 1, 57-70, doi:10.1016/0001-6160(84) 90202-5

${ }^{13}$ G. R. Johnson, W. H. Cook, Fracture characteristics of three metals subjected to various strains, strain rates, temperatures and pressures, Engineering Fracture Mechanics, 21 (1985) 1, 31-48, doi:10.1016/ 0013-7944(85)90052-9

${ }^{14}$ F. J. Zerilli, R. W. Armstrong, Dislocation-Mechanics Based Constitutive Relations for Material Dynamics Calculations, Journal of Applied Physics, 61 (1987) 5, 1816-1825, doi:10.1063/1.338024

${ }^{15}$ K. P. Rao, Y. K. D. V. Prasad, Neural network approach to flow stress evaluation in hot deformation, Journal of Materials Processing Technology, 53 (1995) 3-4, 552-566, doi:10.1016/0924-0136(94)01744-1

${ }^{16}$ Y. C. Lin, M. Chen, J. Zhong, Effect of temperature and strain rate on the compressive deformation behavior of $42 \mathrm{CrMo}$ steel, Journal of Materials Processing Technology, 205 (2008) 1-3, 308-315, doi:10.1016/j.jmatprotec.2007.11.113

${ }^{17}$ A. Laasraoui, J. J. Jonas, Recrystallization of Austenite after Deformation at High Temperature and Strain Rates - Analysis and Modeling, Metallurgical Transactions A, 22 (1991) 1, 151-160, doi:10.1007/BF03350957

${ }^{18}$ A. Laasraoui, J. J. Jonas, Prediction of Steel Flow Stresses at High Temperatures and Strain Rates, Metallurgical Transactions A, 22 (1991) 7, 1545-1558, doi:10.1007/bf02667368

${ }^{19}$ F. Chen, F. C. Ren, Z. S. Cui, et al., Constitutive Modeling for Elevated Temperature Flow Behavior of $30 \mathrm{Cr} 2 \mathrm{Ni} 4 \mathrm{MoV}$ UltraSuper-Critical Rotor Steel, Journal of Iron and Steel Research, International, 21 (2014) 5, 521-526, doi:10.1016/S1006-706X(14) 60081-9

${ }^{20}$ C. Zener, J. H. Hollomon, Effect of strain rate upon plastic flow of steel, Journal of Applied Physics, 15 (1944) 1, 22-32, doi:10.1063/ 1.1707363

${ }^{21}$ F. Chen, G. Feng, Z. Cui, New Constitutive Model for Hot Working, Metallurgical and Materials Transactions A, 47 (2016) 3, 1229-1239, doi:10.1007/s11661-015-3280-y

${ }^{22}$ Y. V. R. K. Prasad, S. Sasidhara, Hot Working Guide: A Compendium of Processing Maps, ASM International, 1997, 545

${ }^{23}$ H. Mirzadeh, A. Najafizadeh, Prediction of the critical conditions for initiation of dynamic recrystallization, Materials \& Design, 31 (2010) 3, 1174-1179, doi:10.1016/j.matdes.2009.09.038

${ }^{24}$ N. Hansen, D. Kuhlmann-Wilsdorf, Low energy dislocation structures due to unidirectional deformation at low temperatures, Materials Science \& Engineering, 81 (1986), 141-161, doi:10.1016/ 0025-5416(86)90258-2

${ }^{25}$ X. M. Chen, Y. C. Lin, D. X. Wen, et al., Dynamic recrystallization behavior of a typical nickel-based superalloy during hot deformation, Materials \& Design, 57 (2014) 5, 568-577, doi:10.1016/j.matdes. 2013.12.072

${ }^{26}$ H. Zhang, G. Chen, Q. Chen, et al., A physically-based constitutive modelling of a high strength aluminum alloy at hot working conditions, Journal of Alloys and Compounds, 743 (2018), 283-293, doi:10.1016/j.jallcom.2018.02.039

${ }^{27}$ F. Chen, H. Wang, H. Zhu, et al., High-temperature deformation mechanisms and physical-based constitutive modeling of ultra-supercritical rotor steel, Journal of Manufacturing Processes, 38 (2019) 2, 223-234, doi:10.1016/j.jmapro.2019.01.021

${ }^{28}$ B. Gong, X. W. Duan, J. S. Liu, et al., A physically based constitutive model of as-forged 34CrNiMo6 steel and processing maps for hot working, Vacuum, 155 (2018), 345-357, doi:10.1016/j.vacuum.2018.06.022 